\title{
CHARACTERIZATION OF COMPOST GRADES ORIGINATED BY DRY FRACTIONATION FOR VARIOUS PARTICLE SIZE OF COMPOST PRODUCED BY SOME AGRICULTURE RESIDUES
}

\author{
Y.A. El-Tahlawy, Soad Y. El-Sayed and Hend M. El-Egemey \\ Agricultural Microbiology Department, Soils, Water and Environ. Res. Inst., ARC, Giza, Egypt.
}

Received: Dec. 16,2017

Accepted: Dec. 25, 2017

\begin{abstract}
Composts are varied in their properties because of the variation in the raw materials and composting management. The current study aims to apply the dry fractionation for three end-product composts of rice straw, bagasse and cotton stalks. In addition to the unfractioned compost (GO), the fractionation distributed particles into 6 grades in particle size, namely, G1 > 2.8, G2= $2-2.8, G 3=1.7-2, G 4=1-1.7, G 5=0.6-1, G 6=0.43-0.60$ and $G 7<0.43$ $\mathrm{mm}$. The compost grades were characterized for agrochemicals and biological properties depending on various particle size. Composted rice straw (SC) displayed the smallest particle size $(0.69 \mathrm{~mm})$ with the most homogeneity $(2.19 \mathrm{~mm})$ followed by compost of bagasse $(B C)$ and cotton stalk (CC) with particle size 1.15 and $1.26 \mathrm{~mm}$ and homogeneity 2.64 and $2.68 \mathrm{~mm}$, respectively. Except bulk densities or $\mathrm{pH}$, the general overall trend indicated significant decreases in electrical conductivity, organic matter, $\mathrm{C} / \mathrm{N}$ ratio, nitrogen and microbial activity as particle size decrease. The fractions of finest particle size recorded an improvement in the germination present and embryo radicals of cress seeds as compared coarser fractions. From the research that has been conducted, it is possible to conclude that dry fractionation is an appropriate simple technique can be implemented to reform custom-made composts improve and/or overcome less maturity, salinity, orientation, agrochemicals variation and/or financial issues encountered with stakeholders in the field of waste recycling.
\end{abstract}

Key words: Agriculture residues, compost, Particle size grades, Biological and agrochemicals properties.

\section{INTRODUCTION}

In most areas of Egypt, the current solid waste stream has an adequate percentage of organic materials, which makes the composting a desirable alternative option to be considered for Egyptian solid waste management systems and adopted for organic/natural fertilizers production. However, Egyptian Environmental Affairs Agency-"EEAA" (2003) reported that many technical problems and poor management of compost manufacture lead to higher production costs and ultimately financial losses.

Compost is a stabilized and sanitized product of organic matter composting, compatible and beneficial to plant growth. The composting is a process of organic matter biotransformation under controlled conditions. During biotransformation, the complex compounds are biodegraded or segmented into simpler elements that again condensed with others to biosynthesize of more other complex molecules (Insam and de Bertoldi 2007). Because of the variation in the primary materials, bulking agents and their mixing proportions as well as the composting methods and management, the compost outcome products have inherent heterogeneity in their maturity and stability criteria. Such this heterogeneity displayed as fluctuations, not only in their agrochemicals or biological contents, but also in the particle size distribution of the final product. Such facts indicate the formation of biotransformed particles qualitatively and quantitatively varied in its physical, agrochemical and biological properties depending on the raw materials and management. 
By far, the particle size is an important physical property that characterizes most solid materials. Measurement of particle size distributions routinely carried out across a wide range of industries and is often a critical parameter in the manufacture of many products. Measuring particle size distributions and understanding how they affect the products and processes can be critical to the success of many manufacturing businesses (Matus et al., 1997; Doublet et al., 2010; Fangueiro et al., 2010 and Wang and Ai 2016).

As far as we are knowing, there have been scarce studies interesting in the trait of particle size distribution of composted agricultural residues as a targeted technique for maximum efficiency of the compost to be oriented, overcome problems such as low maturation. However, many documents, interest in particle size fractionation, focus on soil health, agrochemicals, removal of heavy metals or impurities or evaluation of compost quality. Two ways for fractionation being applied on compost, dry or wet fractionation. Dry particle-size fractionation includes sieving of total dry compost while wet fractionation includes dispersion of compost in water then followed by sieving. According to Doublet et al., (2010), wet fractionation of compost displayed a more realistic particlesize distribution compared to dry method. Coarser fractions remained less transformed and more degradable, and induced $\mathrm{N}$ immobilization.

Regarding the soil health, Gomez-Munoz et al., (2011) demonstrate the economic feasibility of size distribution characterization for olive mill pomace compost (COMP) to undertake an industrially-based fractionation of composts and thereby generate different composts with the desired qualities through particular combinations of different particle sizes. Optimized COMP with the $<1 \mathrm{~mm}$ fraction providing higher quality compost used as a soil conditioner to improve the structure and increase the organic matter in these poorer soils as well as increase the storage of soil organic Carbon. Also, study with Lata Verma and Marschner (2013) concentrated on microbial biomass and soil phosphorus pools as affected by the particle size of garden waste compost and soil properties. The study showed an increase in microbial biomass and $\mathrm{P}$ availability by finest compost size fraction due to its high surface area-volume ratio and higher decomposability compared to the coarser fraction.

Agrochemicals and nutrients are among the most important criteria that characterized by a great variation depending on known haw of compost production as well as the requirements or orientation of application. In this concern, López et al., (2002) stated that the fine fractions $(<2 \mathrm{~mm})$ have lower nutrient contents in comparison with coarse fractions $(>2 \mathrm{~mm})$ which tended to be richer in fertilizing elements. Also, Zhao et al., (2012) found that, the coarse fractions $(>1.6 \mathrm{~mm})$ have greater concentrations of total- $P$ and total- $\mathrm{N}$ within, compared with total $\mathrm{K}$ concentration, which has inversed distribution pattern. Sharifi and Renella (2015) conducted a physical fractionation for municipal solid waste (MSW) by dry saving to quantify coarse impurities and assess the distribution of nutrients, heavy metals and salinity. The results showed that the removal of selected particle size fractions $<0.8 \mathrm{~mm}$ and coarse impurities could significantly improve the compost quality without reducing its fertilization potential, referring to particle size fractionation is a feasible and sustainable approach to improve composted MSW materials for their safe recycle in agriculture.

Compost evaluation in terms of particle size could indicate further quality information. In the context of such objective, Hanc and Dreslova (2016) evaluated some agrochemical properties of the size fractions of the classical composts vs the vermicomposts. The results indicate the superiority of the finer fractions of vermicomposting to achieve more homogeneous and agrochemical properties final product compared to classical 
composting. However, compost particles that were less than $5 \mathrm{~mm}$ exhibited the better agricultural potential than coarser compost. Also, Haynes et al., (2015) characterized mechanically shredded municipal green wastes, from different origins, for composting by means of seven particle size fractions. With decreasing particle size there was a decrease in organic $C$ content and an increase in macronutrient, micronutrient and ash content, which reflect the lignified woody nature material in the larger particle fractions and of green stems and leaves and soil in the smaller particle sizes. Compared with simply analyzing a bulk sample, particle size fractionation is an appropriate way for analyzing and provides additional information about the materials. Ndegwa and Thompson (2001) evaluated integrated systems of compost-vermicomposting using particle size analysis. The evaluation reveals substantial reductions in size in all the systems but more reduction was of nutrients in the smaller sized fractions means referring the practice of using large particle sizes for green fuel and/or mulch does not greatly affect nutrient cycling via green waste composting.

The current study aims to apply the physical dry fractionation for three endproduct composts of three different agricultural residues. The unfractionated compost and generated fractions were characterized for agrochemicals and biological depending on various particle size fractions.

\section{MATERIALS AND METHODS Getting on composts:}

Three miscellaneous composts, as final outcome products ready to apply, were collected from Soil, Water and Environment Research Institute (SWERI), ARC, Giza, Egypt. Such miscellany has been achieved by using various sources of primary materials, namely, rice straw, bagasse and cotton stalks in the three heaps. In addition, each heap was mixed with farmyard manure, rock phosphate, feldspar, bentonite, urea and elemental sulfur at rates of 10,5, 5, 10, 1 and
$1 \% \mathrm{w} / \mathrm{w}$, respectively, as well as vinasse solution and lignocellulosic inoculant (mixture of Trichoderma harzianum and Trichoderma viridi) at rates of $1 \% \mathrm{v} / \mathrm{w}$, respectively, were add as bulking agents and/or amendments (Owis et al., 2016). After three months of composting, all heaps were enriched with a mixture of rhizobacteria inoculant (Bacillus polymyxa, Serratia mercescens and Pseudomonas fluorescens) and left for curing for another 30 days.

\section{Fractionation and gradation:}

Representative samples of each compost type were air dried and subsamples of $3 \mathrm{Kg}$ were used for its fractionation. The subsamples were passed over sieves, stacked in a descending opening size, ASTM numbers of $7,10,12,18,30$ and 40 Tylerequivalent mesh, down to the pan. Shaking process was carried out for such sieves stack distributed the particles into fractions of 6 grades in particle size, namely, $\mathrm{G}_{1}>2.8, \mathrm{G}_{2}=$ $2-2.8, \mathrm{G}_{3}=1.7-2, \mathrm{G}_{4}=1-1.7, \mathrm{G}_{5}=0.6-1, \mathrm{G}_{6}=$ $0.43-0.60$ and $G_{7}<0.43 \mathrm{~mm}$, respectively. The retained mass of each fraction was weighted and recorded. The fractionation process was replicated three times for each compost type.

Geometric mean $\left(d_{i}\right)$ for every two sequenced sieves, in the stack, was used to estimate the particle size average $\left(d_{g w}\right)$ of fraction retained on the $i^{\text {th }}$ sieve. The fitness and homogeneity/heterogeneity degrees, on a weight basis of applied composts, were estimated as a particle size average $\left(d_{g w}\right)$ and a geometric standard deviation $\left(S_{g m}\right)$, respectively, as adopted by Pfost and Headley (1976) as following:

$$
d_{i}=\left(d_{o} \times d_{u}\right)^{0.5}
$$

Where $d_{o}$ is a diameter opening of the $i^{\text {th }}$ sieve and $d_{u}$ is a diameter opening sieve proceeding the $\mathrm{i}^{\text {th }}$ sieve:

$$
\begin{gathered}
d_{g w}=\log ^{-1}\left[\frac{\sum\left(W_{i} \log d_{i}\right)}{\sum W_{i}}\right] \\
S_{g w}=\log ^{-1}\left[\frac{\sum W_{i}\left(\log d_{i}-\log d_{g w}\right)^{2}}{\sum W_{i}}\right]^{0.5}
\end{gathered}
$$

where $W_{i}$ is the fraction weight retained on the $\mathrm{i}^{\text {th }}$ sieve. 
Accordingly, plus to the unfractionated raw compost $\left(\mathrm{G}_{0}\right)$, seven fractions of different grades in particle size were derived from each compost type as shown in Table 1.

The fractions as well as un-sieved composts, as a control, were milled to be less than $0.4 \mathrm{~mm}$ and stored for further assay of physical, agrochemicals and biological characters of generated grades.

\section{Analytical methods: Physical properties:}

The dry matter was gravimetrically calculated from compost samples dried at $105 \pm 5^{\circ} \mathrm{C}$ (Rynk 2000). The bulk density was determined using the core method according to Schaub-Szabo and Leonard (1999).

\section{Agrochemical properties:}

Both compost $\mathrm{pH}$ and electrical conductivity were determined according to the methods described by Page et al., (1982). Values of $\mathrm{pH}$ were measured on samples suspended into distilled water at a ratio of 1:10 (w/v dry basis) using CONSORT ${ }^{\circledR} \mathrm{C} 830$ $\mathrm{pH}$-meter and Compost EC (dS m${ }^{-1}$ ) was measured in compost extract 1:10 compost: water (w/v) using $Y S \mid{ }^{\circledR}$ model 35 conductance meter.

Organic matter (OM\%) was calculated as a loss on ignition (LOI) at $550^{\circ} \mathrm{C} \pm 55^{\circ} \mathrm{C}$ for $2 \mathrm{~h}$ in a muffle furnace, LabTech ${ }^{\circledR}$ Co. LEF203P model (Iglesias Jiménez and Pérez García 1992).

Total nitrogen, phosphorus or potassium were determined in digests obtained from the wet digestion of compost samples $(0.5 \mathrm{~g})$, using a mixture of sulphuric/perchloric acids $(10 \mathrm{ml})$ as described by Chapman and Pratt (1961). Total nitrogen (TN) was measured by the Kjeldahl method using a Gerhardt Vapodest (VAP20) system. Total phosphorus (TP) was determined calorimetrically (Jenway 67 Series Spectrophotometer) by the molybdenum blue method. Total potassium (TK) was measured using Jenway PFP7 flame emission photometer (Faithfull 2002).

\section{Biological properties:}

Nutrient media (NM), Cooke Rose Bengal Agar (CRB) and Czapek Peptone Yeast Agar (CPY) were prepared according to Atlas (2004) for a total viable count of bacteria, fungi, and actinomycetes, respectively, using a spread plate counting technique as follow:

Moisture of composts were processed to achieve level up to about $50-60 \%$ of WHC, indicated by "fist test" for some handfuls of compost were squeezed with hand without water release but compacted (Rynk 2000), and steadied at room atmosphere for three days. Three subsamples were tested for dehydrogenases enzymes activity (DH-ase) and potential static respiration index (PSRI) was determined on the base of $\mathrm{CO}_{2}$ production according to Casida (1977) and Trautmann and Krasny (1998), respectively.

The germination index was assayed according to Trautmann and Krasny (1998) using cress seeds (Lepidium sativum L.) and distilled water as a control. The relative seed germination (SG), relative root elongation (RE) and germination index (GI) as follows:

Table 1: Sieves opening and particle size average (di) of fraction retained on a sieve.

\begin{tabular}{cccc}
\hline Fraction grade & $\begin{array}{c}\text { Sieve No. } \\
(\text { ASTM })\end{array}$ & $\begin{array}{c}\text { Sieve opening } \\
(\mathrm{mm})\end{array}$ & $\begin{array}{c}\text { di } \\
(\mathrm{mm})\end{array}$ \\
\hline $\mathrm{G}_{0}$ & Unfractionated & - & - \\
$\mathrm{G}_{1}$ & 7 & 2.80 & 3.06 \\
$\mathrm{G}_{2}$ & 10 & 2.00 & 2.37 \\
$\mathrm{G}_{3}$ & 12 & 1.70 & 1.84 \\
$\mathrm{G}_{4}$ & 18 & 1.00 & 1.30 \\
$\mathrm{G}_{5}$ & 30 & 0.60 & 0.77 \\
$\mathrm{G}_{6}$ & 40 & 0.43 & 0.50 \\
$\mathrm{G}_{7}$ & $\mathrm{Pan}$ & - & 0.36 \\
\hline
\end{tabular}

*American Standard Test Sieve Series 


$$
\begin{gathered}
S G(\%)=\frac{\text { germinated seeds } \text { No. } \text { in compost extract }}{\text { seeds germinated } \text { No. in control }} \times 100 \\
R E(\%)=\frac{\text { root length mean in compost extract }}{\text { root length mean in control }} \times 100 \\
G I=\frac{S G(\%) \times R E(\%)}{10,0000}
\end{gathered}
$$

where SG\% is the germination percentages of each grade extract; RE\% the mean of the root lengths of the samples and $\mathrm{GI}$ is Germination index. The compost extract was obtained at extraction ration of 1:10 (compost:water w/v dry base).

\section{Statistical analyses}

All statistical analyses were performed using CoStat version 6.450 (Copyright(c) 1998-2017 CoHort) Software. One way randomized blocks (CRB) design at a 95\% confidence level, followed by Tukey's HSD at Significance Level 0.05 for post hoc analysis.

\section{RESULTS AND DISCUSSION Physical properties: Particle size distribution}

Data in Table 2 shows the geometric mean size $\left(d_{g w}\right)$ and standard deviation $\left(S_{g w}\right)$ of the three composts applied to the fractionation process. Composted rice straw (SC) displayed the smallest particle size $(0.69 \mathrm{~mm})$ with the most homogeneity $(2.19$ $\mathrm{mm}$ ) followed by compost of bagasse (BC) and cotton stalk (CC) with particle size of 1.15 and $1.26 \mathrm{~mm}$ and homogeneity 2.64 and 2.68 $\mathrm{mm}$, respectively. The results indicate about the miscellany of compost products in the degradation degree and confirm the previous results of Owis et al., (2016) who stated, that the heap of rice straw exhibited the most microbial activity and organic matter degradation at the active stage of composting, were rather than other heaps of bagasse and cotton stalks. Mears et al., (1975) found that the particle size of during composting of swine and municipal refuse were about 3times the particle size oh swine waste alone or mixed with straw. This clear particle size to be a reliable indicator of stages of decomposition.
Based on the particles size grade, Figure 1 depicts some aspects of the fractions distribution originated from each compost type including the weight, volume, and percentage of each fraction. The fractions content were varied in the weight and volume depending on different opening size between and/or within composts. On such context and in between compost type, the composted rice straw (SC) contains the largest amounts of very fine particles $\left(\mathrm{G}_{5} \leq 0.6 \mathrm{~mm}\right)$ by $66.26 \%$ as compared with 37.28 or $29.17 \%$ of composted bagasse (BC) or cotton stalk (CC), respectively. In addition and within each compost type, the grade $\mathrm{G}_{3}$ (retained on $1.7 \mathrm{~mm}$ ) recorded the lowest weight in all the composts with ratio $1.89,3.89$ and $6.2 \%$ in SC, BC and CC, respectively. However, the rice straw compost was characterized by highest ratio of $\mathrm{G}_{6}$ and $\mathrm{G}_{7}$ grade with 28.60 and $37.66 \%$ against $13.73 \%$ for $\mathrm{G}_{1}$ (the coarsest grade). Conversely, the bagasse or cotton composts had the highest contents of grade $\mathrm{G}_{1}$ (32.32 or 31.68\%) against 15.93 and $21.34 \%$ or 9.42 and $19.74 \%$ for $\mathrm{G}_{6}$ and $\mathrm{G}_{7}$, respectively. Generally, the obtained results fairly closed to Saha et al., (2013); Sharifi and Renella (2015) for the MSW (municipal solid waste) compost. However, the variation in the fractions distribution could be due to differences in the biodegradability of the primary composted feedstock. The bagasse or cotton feedstock is higher in the recalcitrant components than rice straw which could hamper the degradation during composting. This is harmony with Hanc and Pliva (2013) and Hanc and Dreslova (2016), whose attributed the differences in the particle size distribution to the presence of components (e.g. branches) in garden feedstock, fibrous character of straw or dewatered digestate, which are more difficult to degrade, contributed to the high proportions of the coarser fractions. 
Table 2: Particle size features of raw composts applied for the fractionation.

\begin{tabular}{lcl}
\hline Compost type & $d_{g w}(\mathrm{~mm})^{\star}$ & $S_{g w}(\mathrm{~mm})^{\star \star}$ \\
\hline Rice straw (SC) & $0.69 \pm 0.16^{\star \star *}$ & $2.19 \pm 0.23$ \\
Bagasse (BC) & $1.15 \pm 0.15$ & $2.64 \pm 0.15$ \\
Cotton stalk (CC) & $1.26 \pm 0.06$ & $2.68 \pm 0.02$ \\
\hline
\end{tabular}

${ }^{*} d_{g w}$ is geometric mean of particle size on basis of mass.

** $S_{g w}$ is geometric standard deviation of particle size on basis of mass.

*** Average \pm standard deviation.

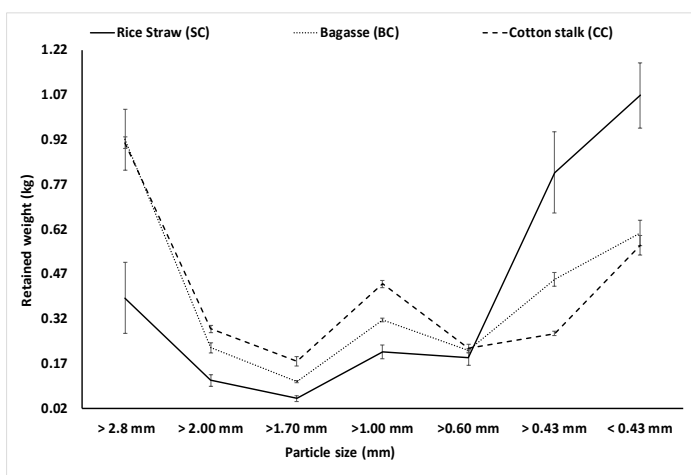

(A) Weight distribution of retained fractions.

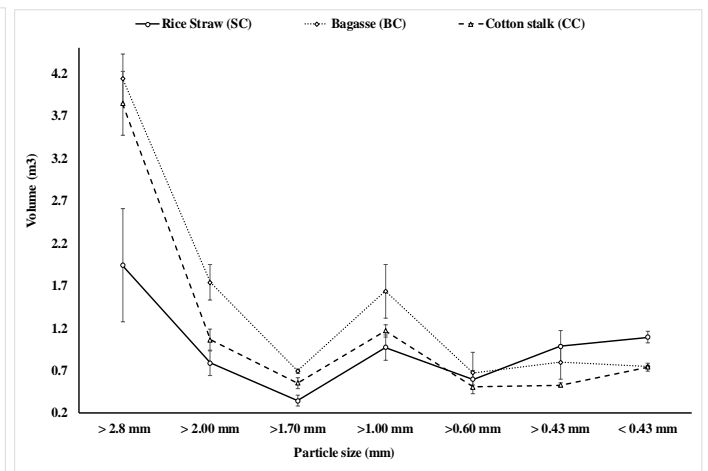

(B) Volume distribution of retained fractions.
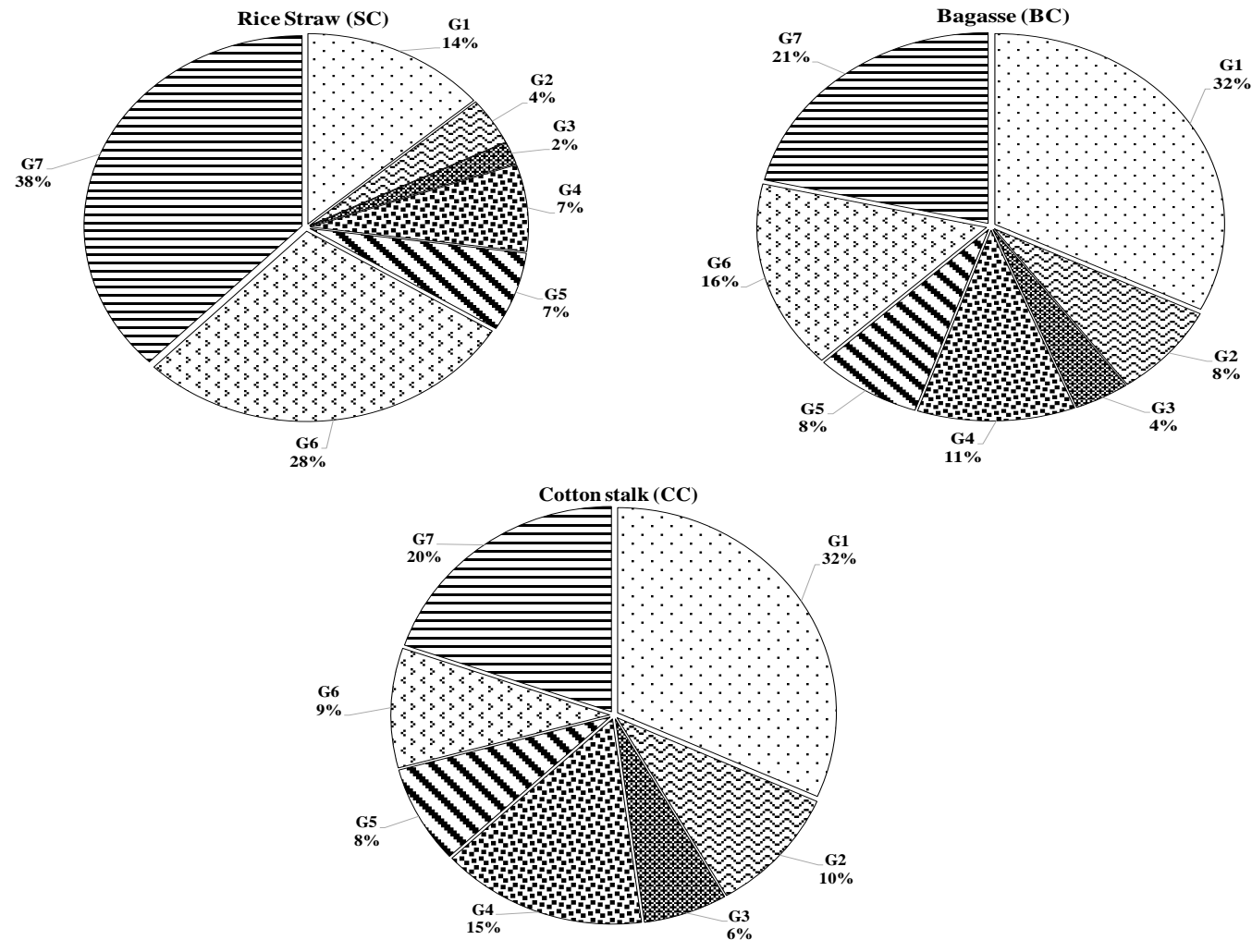

(C) Proportion particle size fraction in composts.

Figure 1. Compost fractions representation based on the particle size. 


\section{Bulk density:}

The bulk densities of different composts grades are represented in Figure 2 as individually and overall trend by columns and line, respectively. The general overall trend indicates a significant increase in the bulk density as particle size decrease. Also, the finest grades, with particle size less than $0.6 \mathrm{~mm}$, revealed increases in the bulk density values (ranged from 0,528 to 0.964 $\mathrm{g} / \mathrm{cm}^{3}$ ) as compared with coarser ones, of particle size more than $0.6 \mathrm{~mm}$ (ranged from 0.129 to $0.514 \mathrm{~g} / \mathrm{cm}^{3}$ ), up to unfractionated composts.

The bulk density expresses the mechanical status of compost such as strength, porosity or capability of compaction or handling which has a consequent to how much the compost could be occupied at a certain space, such as a truck of a given size. Also, in farming sound, the bulk density of compost directly play a vital role on soil physical properties as indicated by bulk density and porosity of soils or indirectly on the grown plants in such soils (Celik et al., 2010; Gaiotti et al., 2017 and Padilla et al., 2017). Because the bulk density is a function porosity, the variation in between fractions values and/or it parent compost could be attributed to filtration of the degraded materials which gradually varied in their particle size, and in turn their porosity, depending on the magnitude of degradation. Another observed factor, especially within the very finest grades, is the presence of sandy soils and/or other mineral materials which included within compost manufacture. The results thus obtained are compatible with Schaub-Szabo and Leonard (1999); Zhao et al., (2012) and Haynes et al., (2015).

\section{Agrochemical properties: Compost $\mathrm{pH}$ and EC (dS $\left.\mathrm{m}^{-1}\right)$}

Compost $\mathrm{pH}$ and $\mathrm{EC}\left(\mathrm{dS} \mathrm{m}{ }^{-1}\right)$ are charted into Figure 3 by line and columns for the overall grades of the typical particle size and ones of each compost type, respectively. In comparison with grades of cotton compost (CC), $\mathrm{pH}$ values of bagasse (BC) and rice (SC) shows a significant decrease (Tukey's $\mathrm{HSD}_{0.05}=0.23$ ) by reduced particle size. Whereas, an EC values significantly (Tukey's $\mathrm{HSD}_{0.05}=0.27$ ) depended upon the particle size with higher values in the coarse fractions (1-2mm) especially for rice and bagasse composts.

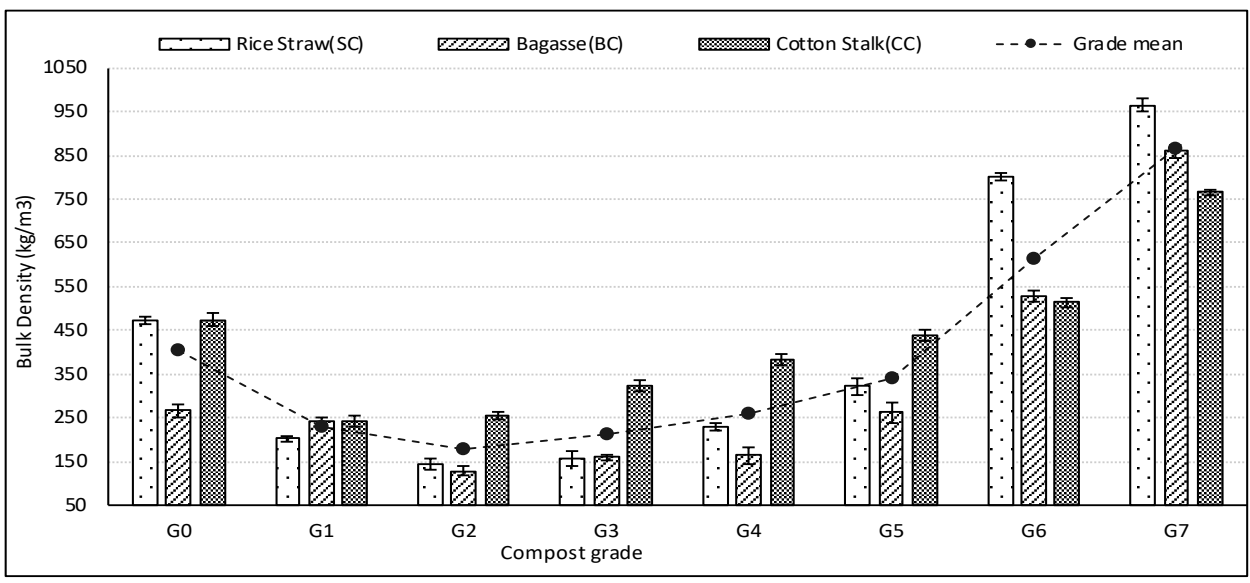

Figure 2. Bulk density of composts grades generated from fractionation.

Columns: grades for each compost type. Line: mean value of the same particle size. 

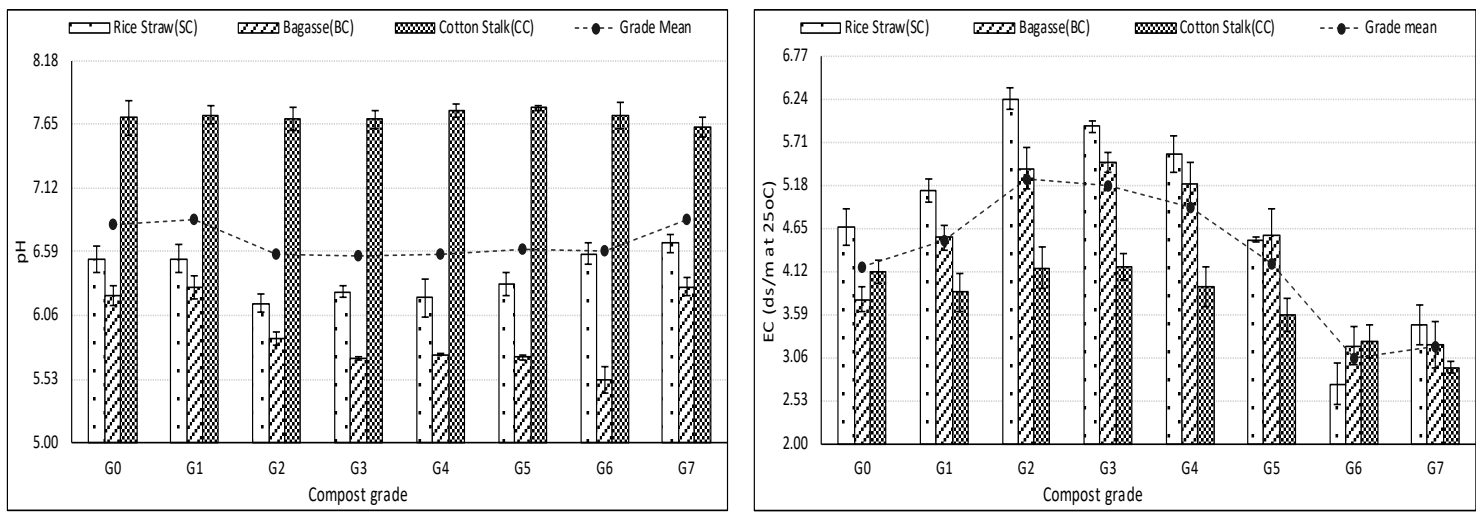

Figure 3. Compost $\mathrm{pH}$ and $\mathrm{EC}\left(\mathrm{dS} \mathrm{m}^{-1}\right)$ of composts grades generated from fractionation.

Columns: grades for each compost type. Line: mean value of the same particle size.

Paradoxically, Lata Verma and Marschner (2013) found that fractionated garden waste compost into fractions with $>5$ to $<3 \mathrm{~mm}$ particle size without differences in $\mathrm{pH}$ values. Also, Zhao et al., (2012); Sharifi and Renella (2015) attributed the increase in EC as fractions particle size of municipal solid wastes decrease, to the positive relationship between specific surface areas of different particle sizes with their cation adsorption capacity. Such discrepancy with our date may be due to the differences the composted raw materials. However, López et al., (2002) found a decrease in the EC as the particle size decrease which consistent with our results. Because the importance of $\mathrm{pH}$ and $\mathrm{EC}$ in controlling soil health, the compost $\mathrm{pH}$ or EC values could be positively managed by such physio-fractionation process into grades with less soluble ions and organic acids in an attempt to mitigate excessive salinity and/or low $\mathrm{pH}$ values.

\section{Organic matter and nutrients:}

The content percentage of both organic matter and some macronutrients, namely N.P.K., of applied composts and their fractions are outlined into Figure 4 with lines and columns for values of typical particle size and within each compost type, respectively. With exception phosphorus, the fractionation process, generally, outputted a reduction in the organic matter, $\mathrm{C} / \mathrm{N}$ ratio and N.P.K. values of applied composts, especially in finest grades $(<1 \mathrm{~mm})$ as compared the coarser $(>1.7 \mathrm{~mm}$ ) or non-fractionated composts. Data in Table 3 shows the content percent of accumulated organic matter and the studied nutrients within different fractions. Coarser fractions (more than $1 \mathrm{~mm}$ ) of SC; BC or CC compost gathered $77.75,64.78$, 55.76 and $69.13 \% ; 74.47,68.27,53.82$ and $68.53 \%$ or $65.29,62.49,52.03$ and $61.43 \%$ against finest fractions (less than $1 \mathrm{~mm}$ ) $22.25,35.22,44.24$ and 30.87 ; $25.53,31.73$, 46.18 and 31.47 or $34.71,37.51,47.97$ and 38.57 of organic matter, N, P and K, respectively.

The mechanisms leading to the distribution of $\mathrm{N}, \mathrm{P}$ and $\mathrm{K}$ within compost fractions have been early proposed by Ding et al., (2004) who stated that organic form of phosphorus sustains it higher in coarse compost size fractions. Whereas, the presence of potassium inorganic form increases its concentration in fine compost fractions. As compost particles decrease, in organic components increase, thus mineral content increases. López et al., (2002) and Lata Verma and Marschner (2013) disagree our results about nutrient contents. Also, Doublet et al., (2010) found that dry fractionation of sewage sludge deduce finest fraction $(0-50 \mu \mathrm{m})$ characterized by lower content of total organic carbon or $\mathrm{C} / \mathrm{N}$ ratio 

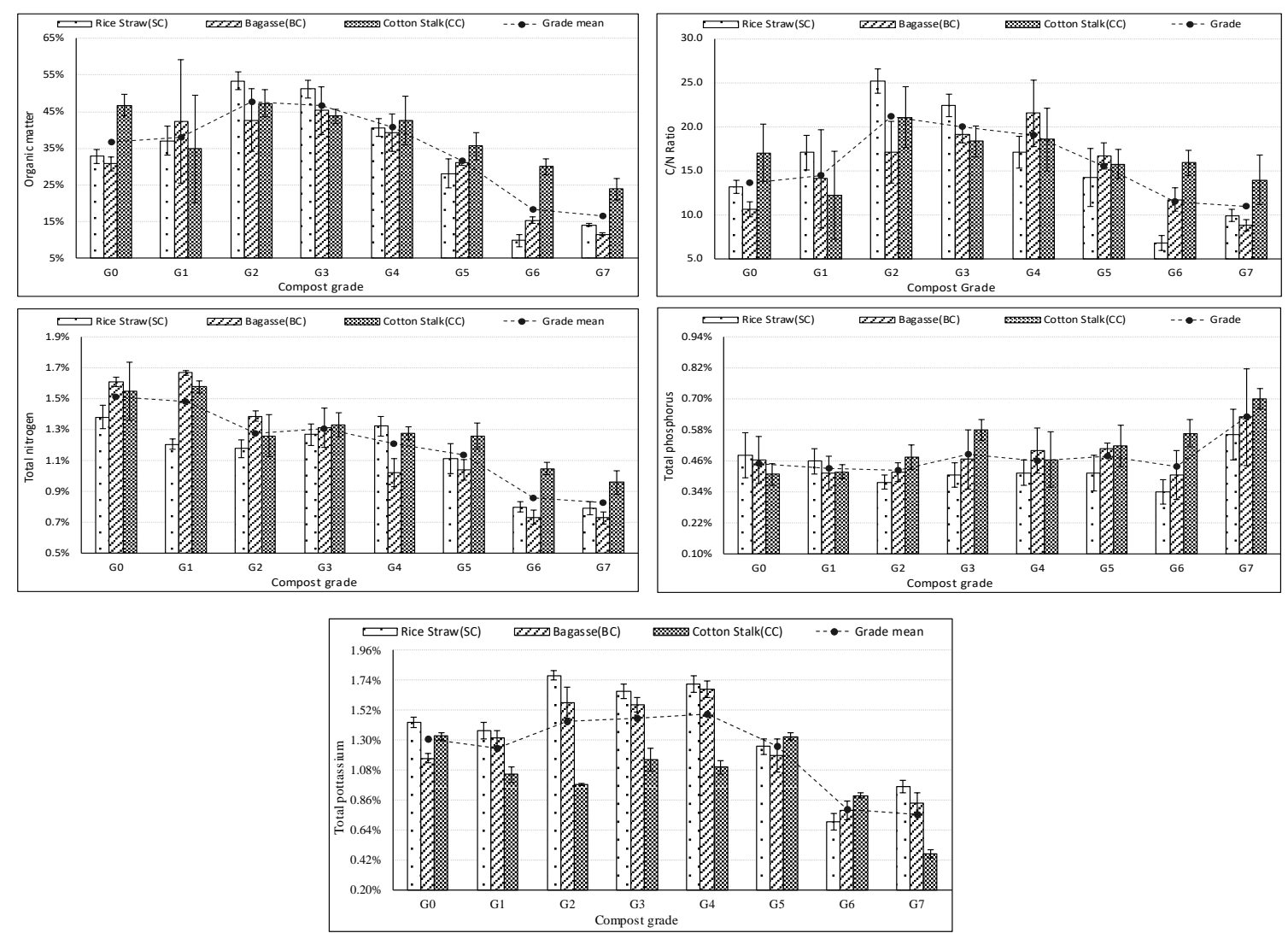

Figure 4. Organic matter and macronutrients content of composts grades generated from fractionation.

Columns: grades for each compost type. Line: mean value of the same particle size.

but higher nitrogen than coarser $(5-20 \mathrm{~mm})$ because the dry fractionation was not able to disrupt organic matter aggregates in compost or to peel off the fine particles aggregated on the coarser particles. Gomez-Munoz et al., (2011) found similar results about organic matter, TN, TP or TK for composted olive mill pomace. In other studies, Zhao et al., (2012) found similar results for municipal solid waste compost and by Hanc and Dreslova (2016) for biowaste vermicompost.

\section{Biological properties: Microbial properties:}

Changes in total bacteria, fungi, and actinobacteria as a result of fractionation process are outlined into Figure 5 for all grades originated form three compost types. Although the differences between parents of compost types, an overall pattern of the microbial load tend to decline as particle size decrease. The fungi did not reveal a significant variation (Tukey's HSD $0.05=1.52$ ) as compared with bacteria (Tukey's HSD 0.05 $=1.17$ ) or actinomycetes (Tukey's HSD $0.05=$ 1.15). The effects of fractionation process between were clearly observed by a coarser fraction of particle size $>0.6 \mathrm{~mm}$ as compared with finer ones.

Regarding the microbial activity, Figure 6 represent potential static respiration index (PSRI) along with dehydrogenases activity (DH-ase). The microbial activity match and enforce the microbial count in the courses fractions (G5 > $0.6 \mathrm{~mm}$ ) and significant decrease with lower particle size. The microbial load and its activity indicate the stability of the composted material. Brinton (2000); Thompson et al., (2001) set limits of the $\mathrm{CO}_{2}$ production rate for compost stability ranging from $<2,2-5,5-10,10-20$ and $>20 \mathrm{mg}$ $\mathrm{CO}_{2} \mathrm{C} / \mathrm{g}$ organic carbon/day for very stable, stable moderately stable, unstable and extremely unstable, respectively. 
Table 3. Percentage of accumulated organic matter and some nutrient properties within fractions.

\begin{tabular}{|c|c|c|c|c|}
\hline Particle Size & Organic matter $\%$ & Total-N \% & Total-P \% & Total-K \% \\
\hline \multicolumn{5}{|c|}{ Rice straw compost (SC) } \\
\hline$>2.8 \mathrm{~mm}$ & 15.80 & 15.69 & 15.45 & 14.53 \\
\hline$>2.0 \mathrm{~mm}$ & 38.59 & 31.03 & 28.18 & 33.36 \\
\hline$>1.7 \mathrm{~mm}$ & 60.44 & 47.55 & 41.84 & 50.97 \\
\hline$>1.0 \mathrm{~mm}$ & 77.75 & 64.78 & 55.76 & 69.13 \\
\hline$>0.6 \mathrm{~mm}$ & 89.76 & 79.27 & 69.64 & 82.42 \\
\hline$>0.4 \mathrm{~mm}$ & 93.96 & 89.68 & 81.08 & 89.84 \\
\hline Total & 100.00 & 100.00 & 100.00 & 100.00 \\
\hline \multicolumn{5}{|c|}{ Bagasse compost (BC) } \\
\hline$>2.8 \mathrm{~mm}$ & 18.58 & 21.11 & 12.37 & 14.72 \\
\hline$>2.0 \mathrm{~mm}$ & 37.33 & 38.69 & 24.89 & 32.34 \\
\hline$>1.7 \mathrm{~mm}$ & 57.20 & 55.32 & 38.85 & 49.81 \\
\hline$>1.0 \mathrm{~mm}$ & 74.47 & 68.27 & 53.82 & 68.53 \\
\hline$>0.6 \mathrm{~mm}$ & 88.15 & 81.48 & 69.00 & 81.81 \\
\hline$>0.4 \mathrm{~mm}$ & 94.92 & 90.76 & 81.14 & 90.60 \\
\hline Total & 100.00 & 100.00 & 100.00 & 100.00 \\
\hline \multicolumn{5}{|c|}{ Cotton stalk compost (CC) } \\
\hline$>2.8 \mathrm{~mm}$ & 13.52 & 18.09 & 11.24 & 15.04 \\
\hline$>2.0 \mathrm{~mm}$ & 31.85 & 32.56 & 23.97 & 29.03 \\
\hline$>1.7 \mathrm{~mm}$ & 48.83 & 47.82 & 39.55 & 45.62 \\
\hline$>1.0 \mathrm{~mm}$ & 65.29 & 62.49 & 52.03 & 61.43 \\
\hline$>0.6 \mathrm{~mm}$ & 79.11 & 76.92 & 65.97 & 80.49 \\
\hline$>0.4 \mathrm{~mm}$ & 90.73 & 88.97 & 81.20 & 93.34 \\
\hline Total & 100.00 & 100.00 & 100.00 & 100.00 \\
\hline
\end{tabular}

*Accumulated values estimated according to Zhao et al., (2012).
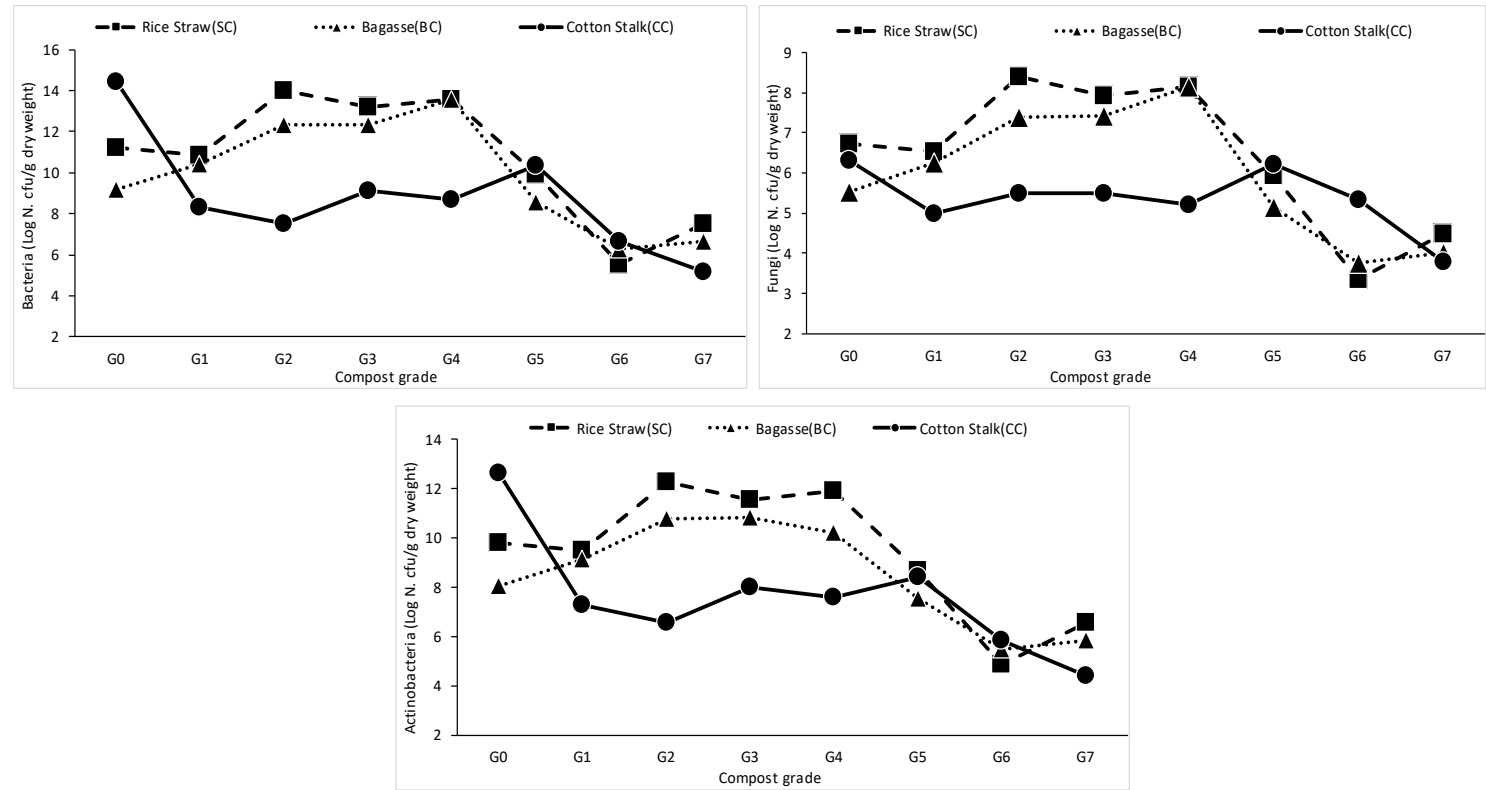

Figure 5. Microbial enumeration of composts grades generated from fractionation. 


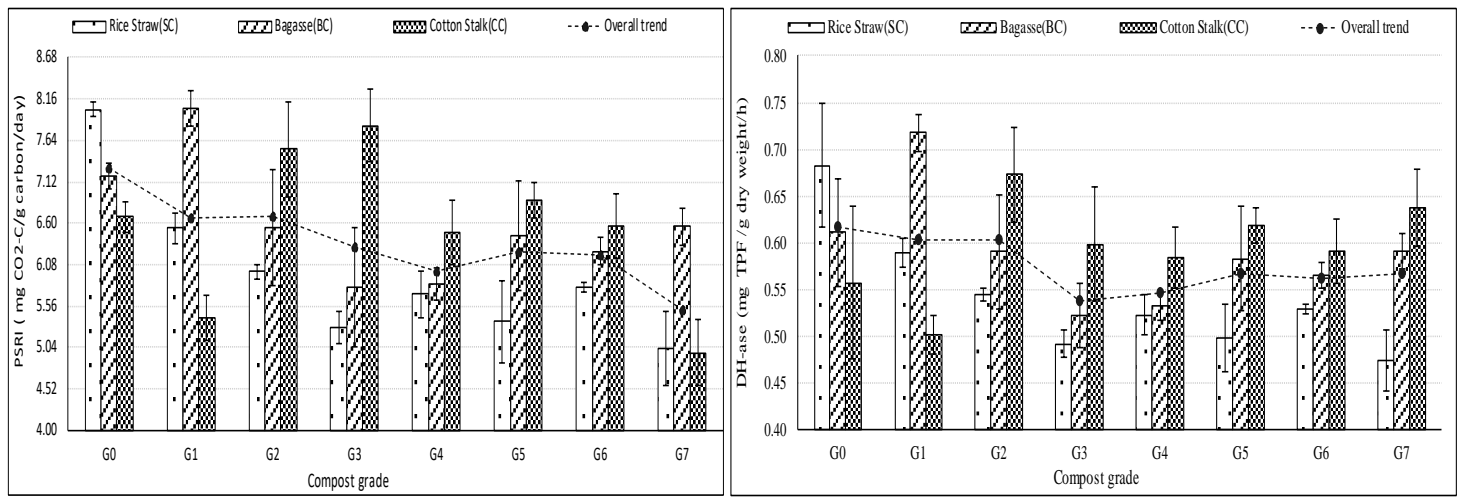

Figure 6. Microbial activities of composts grades generated from fractionation.

Columns: grades for each compost type. Line: mean value of the same particle size.

The quantitative and qualitative characters of organic matter and nitrogen represent limiting factors to the rate of microbial degradation. The research published on dry fractionation in the point view mean classes of microflora and its activities have a paucity. However, the functional groups of microorganisms have studied by Fangueiro et al., (2010) and Haynes et al., (2015) which stated the interrelationship between microbial decomposition and net N mineralization/immobilization within the different particle size fractions in harmony with our results. On the other hand, Lata Verma and Marschner (2013) found that, the finest size fraction, of garden waste compost, have enhanced the effect on microbial biomass and $\mathrm{P}$ availability more than the coarser fraction because its high specific surface area-volume ratio and higher decomposability compared to the coarser fraction.

\section{Phytotoxicity bioassay:}

The phytotoxicity of un-fractionated composts and their generated fraction to estimate whether the grades contains substances that inhibit or stimulate seed germination and/or growth of the radicles of the embryo (Table 4).

Generally, the physical fractionation of composts reveals significant differences in between compost fractions depending on compost type or particles size. Such differences clearly recorded for the percent of germination because the action of a fraction of particle size of particle size more than 0.6 $\mathrm{mm}$ (G5) against finer ones depending on compost type. On the other hand, a great variation in embryo root length showed by G5 finer grades. Because germination index is a function of germination and radical percent, showed slightly decrease as particle size decrease referring to the positive effect of nutrients or growth factors, contained into the composted material, on the roots. According to Gomez-Munoz et al., (2011), germination index of olive mill compost increased as the particle size decreased. The particle size < $1.0 \mathrm{~mm}$ lacked to phytotoxicity $(\mathrm{Gl}=0.8)$ as compared with a particle of $1.0-6.0 \mathrm{~mm}$ $(\mathrm{Gl}=0.5)$ which have some phytotoxicity. 
Y.A. El-Tahlawy, et al.,

Table 4. Phytotoxicity properties of the composts grades generated from fractionation.

\begin{tabular}{|c|c|c|c|c|}
\hline Type & Grade & $\begin{array}{l}\text { Relative seed } \\
\text { germination (\%) }\end{array}$ & $\begin{array}{l}\text { Relative root } \\
\text { elongation (\%) }\end{array}$ & Germination index \\
\hline \multirow{8}{*}{ 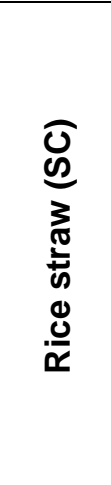 } & G0 & $88.38 \pm 3.71$ & $61.38 \pm 26.84$ & $1.76 \pm 0.07$ \\
\hline & G1 & $89.39 \pm 2.35$ & $84.77 \pm 20.05$ & $1.73 \pm 0.05$ \\
\hline & G2 & $91.90 \pm 0.97$ & $56.66 \pm 5.28$ & $1.60 \pm 0.02$ \\
\hline & G3 & $93.20 \pm 1.18$ & $91.58 \pm 16.65$ & $1.37 \pm 0.06$ \\
\hline & G4 & $89.43 \pm 3.46$ & $103.89 \pm 10.99$ & $1.07 \pm 0.06$ \\
\hline & G5 & $88.55 \pm 1.64$ & $147.94 \pm 5.68$ & $1.03 \pm 0.03$ \\
\hline & G6 & $89.05 \pm 2.38$ & $80.54 \pm 7.44$ & $1.05 \pm 0.04$ \\
\hline & G7 & $92.16 \pm 2.01$ & $113.88 \pm 9.4$ & $1.23 \pm 0.05$ \\
\hline \multirow{8}{*}{ 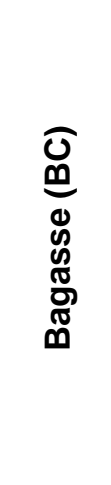 } & G0 & $92.32 \pm 1.59$ & $65.33 \pm 18.99$ & $1.55 \pm 0.06$ \\
\hline & G1 & $76.80 \pm 1.80$ & $76.34 \pm 0.81$ & $0.73 \pm 0.01$ \\
\hline & G2 & $81.00 \pm 6.50$ & $63.35 \pm 9.05$ & $0.82 \pm 0.06$ \\
\hline & G3 & $69.24 \pm 1.15$ & $93.41 \pm 1.32$ & $0.59 \pm 0.01$ \\
\hline & G4 & $80.53 \pm 4.26$ & $82.38 \pm 4.76$ & $0.80 \pm 0.03$ \\
\hline & G5 & $80.93 \pm 8.54$ & $146.27 \pm 13.43$ & $0.81 \pm 0.08$ \\
\hline & G6 & $87.04 \pm 3.04$ & $82.63 \pm 9.95$ & $0.98 \pm 0.05$ \\
\hline & G7 & $90.72 \pm 3.32$ & $142.90 \pm 14.73$ & $1.14 \pm 0.07$ \\
\hline \multirow{8}{*}{ 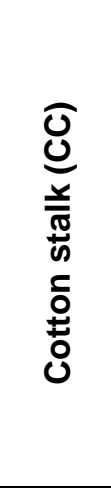 } & G0 & $90.88 \pm 2.12$ & $52.83 \pm 12.14$ & $1.66 \pm 0.03$ \\
\hline & G1 & $92.25 \pm 1.27$ & $69.73 \pm 1.95$ & $1.20 \pm 0.01$ \\
\hline & G2 & $87.35 \pm 5.37$ & $50.62 \pm 13.69$ & $0.99 \pm 0.07$ \\
\hline & G3 & $82.62 \pm 4.48$ & $85.50 \pm 10.11$ & $0.85 \pm 0.05$ \\
\hline & G4 & $74.66 \pm 7.67$ & $82.98 \pm 11.11$ & $0.69 \pm 0.06$ \\
\hline & G5 & $91.77 \pm 1.15$ & $104.54 \pm 5.51$ & $1.16 \pm 0.03$ \\
\hline & G6 & $91.65 \pm 1.20$ & $69.20 \pm 6.4$ & $1.19 \pm 0.03$ \\
\hline & G7 & $93.01 \pm 0.45$ & $90.46 \pm 19.09$ & $1.46 \pm 0.07$ \\
\hline \multicolumn{2}{|c|}{ Tukey's HSD 0.05} & 4.65 & 15.64 & 0.15 \\
\hline
\end{tabular}

* The values represented as mean \pm SD.

\section{Conclusions}

The compost is a product characterized by certain bio-transformed materials under controlled conditions. Such materials formed as a result of progressive biodegradation of raw organic matter to make fractions with various particle size. The dry fractionation could quantitatively and/or qualitatively reproduce special grades of composted material, which potentially differ from parents. From the research that has been conducted, it is possible to conclude that dry fractionation is an appropriate simple technique can be implemented to reform custom-made composts improve and/or overcome less maturity, salinity, orientation, agrochemicals 
variation and/or financial issues encountered with stakeholders in the field of waste recycling. Further research should focus on particle size fractionation with agricultural residues composting in terms of biological criteria including microflora communities, microbial function groups, qualitative organic matter, and plant growth promoters.

\section{REFERENCES}

Atlas, R. M. (2004). Handbook of Microbiological Media. $3^{\text {rd }}$ edition. CRC Press LLC, Boca Raton, Florida, USA.

Brinton, F. W. (2000). Compost Quality Standards \& Guidelines. Compost Quality in America. Woods End Research Laboratory Inc. New York State Association of Recyclers (NYSAR), USA, Woods End Research Laboratory, Inc.: 9 - 38.

Casida, L. E., Jr. (1977). Microbial metabolic activity in soil as measured by dehydrogenase determinations. Appl. Environ. Microbiol., 34: 630-636.

Celik, I., H. Gunal, M. Budak and C. Akpinar (2010). Effects of long-term organic and mineral fertilizers on bulk density and penetration resistance in semi-arid mediterranean soil conditions. Geoderma, 160: 236-243.

Chapman, H.D. and P.F. Pratt (1961). Methods of Analysis for Soils, Plants and Waters. Agriculture Plant University of California, USA, Riversied.

Ding, X., G. LI and Y. LI (2004). Effects of screening and adding night soil on characteristics of MSW compost. AgroEnvironmental Protection, 23: 122-127.

Doublet, J., C. Francou, J. P. Petraud, M. F. Dignac, M. Poitrenaud and S. Houot (2010). Distribution of C and N mineralization of a sludge compost within particle-size fractions. Bioresour. Technol., 101: 1254-1262.

Egyptian Environmental Affairs Agency"EEAA" (2003). Evaluation of composting facilities in Egypt. The Solid Waste Technical Assistance Project, a component of the USAID-funded Egyptian
Environmental Policy Program, conducted in support of EEAA solid waste management activities.

Faithfull, N. T. (2002). International Methods in Agricultural Chemical Analysis: a Practical Handbook. Frist Edition. CABI Publishing London, UK.

Fangueiro, D., M. Gusmão, J. Grilo, G. Porfírio, E. Vasconcelos and F. Cabral (2010). Proportion, composition and potential $\mathrm{N}$ mineralisation of particle size fractions obtained by mechanical separation of animal slurry. Biosystems Engineering, 106: 333-337.

Gaiotti, F., P. Marcuzzo, N. Belfiore, L. Lovat, F. Fornasier and D. Tomasi (2017). Influence of compost addition on soil properties, root growth and vine performances of Vitis vinifera cv Cabernet sauvignon. Scientia Horticulturae, 225: 88-95.

Gomez-Munoz, B., R. Bol, D. Hatch and R. Garcia-Ruiz (2011). Carbon mineralization and distribution of nutrients within different particle-size fractions of commercially produced olive mill pomace. Bioresour. Technol., 102: 9997-10005.

Hanc, A. and M. Dreslova (2016). Effect of composting and vermicomposting on properties of particle size fractions. Bioresour. Technol., 217: 186-189.

Hanc, A. and P. Pliva (2013). Vermicomposting technology as a tool for nutrient recovery from kitchen bio-waste. Journal of Material Cycles and Waste Management, 15: 431-439.

Haynes, R. J., O. N. Belyaeva and Y. F. Zhou (2015). Particle size fractionation as a method for characterizing the nutrient content of municipal green waste used for composting. Waste Manag., 35: 48-54.

Iglesias Jiménez, E. and V. Pérez García (1992). Relationships between organic carbon and total organic matter in municipal solid wastes and city refuse composts. Bioresour. Technol., 41: 265272.

Insam, H. and M. de Bertoldi (2007). Microbiology of the composting process. 
Compost Science and Technology. L. F. Diaz, M. de Bertoldi, W. Bidlingmaier and E. Stentiford. Netherlands, Elsevier: 2548.

Lata Verma, S. and P. Marschner (2013). Compost effects on microbial biomass and soil $\mathrm{P}$ pools as affected by particle size and soil properties. J. soil sci. plant nutrition, 13: 313-328.

López, R., M. D. Hurtado and F. Cabrera (2002). Compost properties related to particle size. Waste management and the environment. D. Almorza, C. Brebbia, D. Sales and V. Popov. Ashurst Lodge, Southampton, UK, WIT Press. 56: 788.

Matus, F. J., J. B. Retamales and P. Sánchez (1997). Effect of particle size and quality of pruning wood residues of asian pear (Pyrus pyrifolia and Pyrus communis) on $\mathrm{C}$ and $\mathrm{N}$ mineralisation in soils of contrasting textures. Acta Horticulturae, 475: 327-337.

Mears, D. R., M. E. Singley and G. Ali (1975). Thermal and physical properties of compost. In: W.J.Jewell (ed.) Ann Arbor Science Publishers, Proceedings of the 7th Agricultural Waste Management, Conference, Cornell University:515-527.

Ndegwa, P. M. and S. A. Thompson (2001). Integrating composting and vermicomposting in the treatment and bioconversion of biosolids. Bioresour. Technol., 76: 107-112.

Owis, A. S., W. M. El-Etr, F. S. F. Badawi, A. A. Abo El-Soud and A. F. M. Abdel-Wahab (2016). Bio-Processing the crop Residues with different amendments for producing high quality compost. Inter. J. Chem.Tech. Res., 9: 43-54.

Padilla, F. M., M. T. Peña-Fleitas, M. D. Fernández, F. del Moral, R. B. Thompson and M. Gallardo (2017). Responses of soil properties, crop yield and root growth to improved irrigation and $\mathrm{N}$ fertilization, soil tillage and compost addition in a pepper crop. Scientia Horticulturae, 225: 422430.
Page, A. L., R. H. Miller and D. R. Keeney (1982). Methods of Soil Analysis. Part 2. Chemical and Microbiological Properties. Second Edition. Wisconsin, USA.

Pfost, H. B. and V. Headley (1976). Methods of determining and expressing particle size - Appendix C. Feed Manufacturing Technology. H. B. Pfost. Arlington, VA, USA, American Feed Manufacturers Association Inc.

Rynk, R. (2000). Monitoring moisture in composting systems. Biocycle, 21: 53-57.

Saha, J. K., N. R. Panwar and M. V. Coumar (2013). Effect of methods of preparation on distribution of heavy metals in different size fractions of municipal solid waste composts. Environ. Monit. Assess., 185: 8815-8821.

Schaub-Szabo, S. M. and J. J. Leonard (1999). Characterizing the bulk density of compost. Compost Science \& Utilization, 7: 15-24.

Sharifi, Z. and G. Renella (2015). Assessment of a particle size fractionation as a technology for reducing heavy metal, salinity and impurities from compost produced by municipal solid waste. Waste Manag., 38: 95-101.

Thompson, W. H., P. B. Leege, P. D. Millner and M. E. Watson (2001). Test Methods for the Examination of Composting and Compost (TMECC). $1^{\text {st }}$. US Composting Council Research and Education Foundation, USA.

Trautmann, N. M. and M. E. Krasny (1998). Composting In The Classroom: Scientific Inquiry For High School Students. $1^{\text {st }}$ edition. Cornell Univ., Athletics, USA.

Wang, Y. and P. Ai (2016). Integrating particle physical geometry into composting degradation kinetics. Bioresour. Technol., 200: 514-520.

Zhao, S., X. Liu and L. Duo (2012). Physical and chemical characterization of municipal solid waste compost in different particle size fractions. Polish Journal of Environmental Studies, 21: 509-515. 


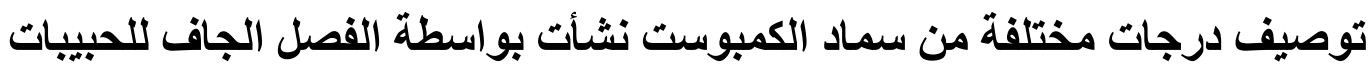

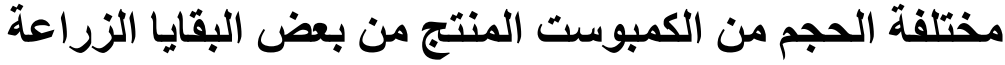

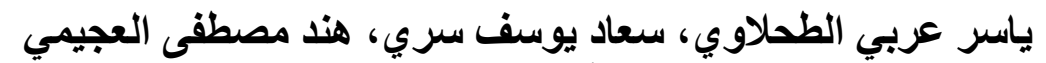

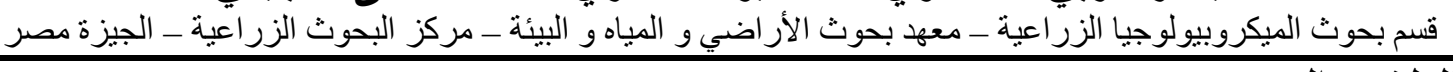
الملخص العربي

تتباين صفات اللسماد العضوي الصناعى (الكمبوست) بسبب التتوع في المو اد المصنوع منهاو كيفة الكئة الإدارة اثناء الانتاج.

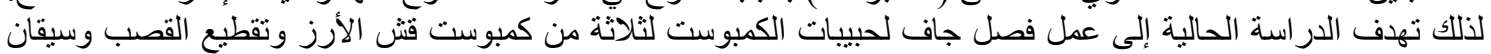

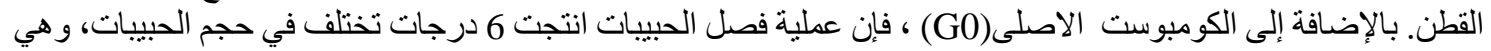

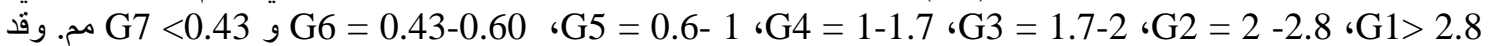

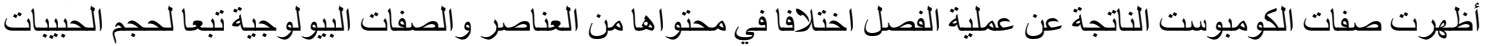

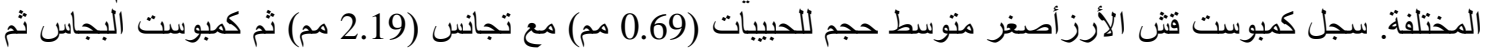

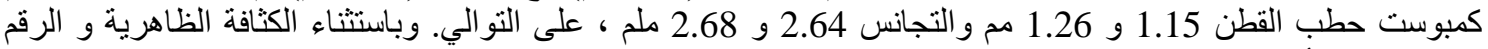

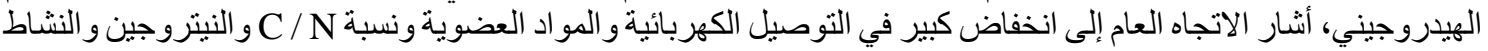

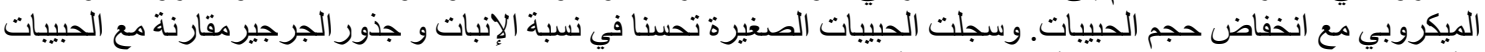

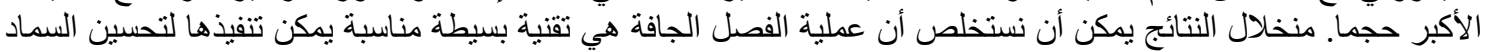

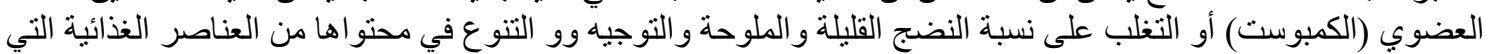
قد تواجة العاملين في مجال إعادة تدوير المخلفات.

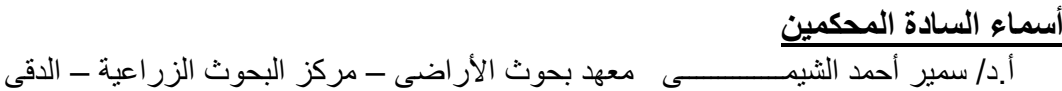

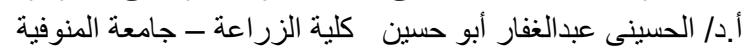

